\title{
SHORT-TERM MACROINVERTEBRATE RECRUITMENT AND SEDIMENT ACCUMULATION: A NOVEL FIELD CHAMBER APPROACH
}

\author{
Jon P. Kochersberger, ${ }^{*} \dagger$ G. Allen Burton Jr., $\dagger \ddagger$ and Kevin W. Custer $\dagger$ \\ $\dagger$ Department of Earth and Environmental Sciences, Wright State University, Fairborn, Ohio, USA \\ $\ddagger$ School of Natural Resources and Environment, University of Michigan, Ann Arbor, Michigan, USA
}

(Submitted 3 November 2010; Returned for Revision 7 February 2011; Accepted 14 December 2011)

\begin{abstract}
Stream-deposited sediment is one of the major stressors affecting stream biota. Several methods exist to quantify stream sediment embeddedness, but they are relatively qualitative and operationally defined. The authors developed a short-term in situ embeddedness chamber method to measure aquatic insect recruitment and associated sediment accumulation in a more quantitative, better replicated manner. With sediment accumulation and aquatic insect recruitment as endpoints, three exposure periods were evaluated (4, 7, and 14 d) on a low-order stream (Honey Creek, New Carlisle, Ohio, USA) and a medium-order stream (Stillwater River, Covington, Ohio, USA). Chamber results show significant positive correlations between newly deposited fine sediment and insect recruitment. Embeddedness was also measured using the more conventional techniques of the Burns method and the U.S. Geological Survey National Water Quality Assessment Program method. This in situ chamber method allows for increased experimental options for assessing the stress of embeddedness and siltation on benthic communities and may prove useful for investigating the resilience of benthic communities after disturbances. Environ. Toxicol. Chem. 2012;31:1098-1106. (C) 2012 SETAC
\end{abstract}

Keywords-Artificial substrate Benthic macroinvertebrates In situ Recruitment $\quad$ Embeddedness

\section{INTRODUCTION}

Aquatic organisms may be affected by multiple stressors. Many studies have clearly demonstrated contaminant "causality" in both laboratory and field settings without having knowledge of the role of habitat as a potential stressor [1]. Both suspended and deposited sediments have been identified as major pollutants of U.S. waters, and their effect on aquatic organisms is well established [2-6]. The adverse impacts of increased sediment loading on stream communities include reduced light penetration, organism smothering, habitat reduction, and introduction of adsorbed contaminants $[1,3,7,8]$. In a recent study, a measure of subsurface fines was strongly related to watershed and riparian percentage of agriculture and was the best indicator of land use among 16 metrics studied [9].

A vital physical characteristic of aquatic habitats, particularly in large-grained sediment systems, is the degree of substrate embeddedness that occurs as a result of fine sediments filling the voids of interstitial spaces in the streambed [4]. Elevated fine sediment loadings can alter hyporheic exchange and associated ecological processes, depending on local hydrologic and geomorphic conditions [10,11]. Streams can experience increased flow disturbances (flooding), which have the ability to affect the geomorphology of the stream (scour and shear stress); subsequently, macroinvertebrate colonization can be affected after these events [12,13]. Substrate changes affected by these increased flow events have been shown to either facilitate macroinvertebrate colonization [12] or hinder colonization [13,14]. High-flow events have the ability to remove fine sediments, redistribute organic matter, and change substrate grain size availability, which can free up habitats or facilitate certain feeding strategies $[12,14]$. As these high-flow

* To whom correspondence may be addressed

(jon.kochersberger@gmail.com).

Published online 23 February 2012 in Wiley Online Library (wileyonlinelibrary.com). events end, fine sediments can be deposited onto existing substrates. This can contribute to embeddedness, and macroinvertebrate diversity has been shown to be negatively affected [15], with some invertebrates even buried alive during these conditions [16].

The ability of lotic communities to recover from disturbances and how they are shaped by disturbances has received much attention. Resilience of the sediment-specific stream community structure has been shown to be related directly to the frequency of disturbance in a particular sediment type, and potential patterns have been observed in the magnitude of change from the initial, predisturbance level of population sizes [17].

Some studies have questioned the reliability of existing embeddedness measures [18,19]. Most embeddedness estimation techniques measure substrate particle height and the corresponding embedded sediment height on that particle. Techniques such as the U.S. Geological Society National Water Quality Assessment (NAWQA) method, the U.S. Environmental Protection Agency (U.S. EPA) method, and the Burns method give the fraction of substrate surface area composed of fine sediment [20-23]. The U.S. Fish and Wildlife Service (U.S. FWS) depth to embeddedness method measures the depth to embeddedness of the particle rather than the fraction that is embedded [22]. Sample size varies with all of these methods; some sample collections are random, and some are restricted to particular bed features (e.g., riffles). The objectives of the present study were to develop an in situ macroinvertebrate survey method that measures both ongoing sediment deposition and macroinvertebrate recruitment to a pebble-like substrate.

\section{MATERIALS AND METHODS}

\section{Experimental design}

This research employed an in situ chamber with an introduced clean, artificial substrate to assess aquatic insect colonization 
and sediment accumulation over periods of 4,7 , and $14 \mathrm{~d}$. The chambers were placed in-stream (three to each in situ tray, totaling eight trays and 24 chambers), and a random sampling scheme was used to sample chambers. Four chambers were retrieved and sampled (both for aquatic insects and sediment, totaling eight chambers) at each of these time points. Four sediment fractions (representing gravel, sand, silt, and clay) were analyzed from sediment that accumulated within the interstitial spaces of the chamber substrate. Furthermore, the porosity of each chamber was estimated using the bulk density of the chamber sediments (determined through a sequential loss on ignition process). The chambers designated for aquatic insect colonization were processed in the laboratory, and all insects were identified to family level for use in determining select macroinvertebrate metrics. Statistical analysis was run between both abiotic and biotic data.

A 10-d sediment toxicity test was conducted using sediment from each site to determine whether any background factors were present that could alter macroinvertebrate colonization. Also, a thorough characterization of the substrate at each site, including percentage of embedded substrate size fraction, as well as water quality parameters and stream flow were monitored to understand the characteristics of each site better. In addition, a U.S. EPA rapid bioassessment protocol was conducted to determine the variation of the aquatic insect community assemblage for each test site [24].

\section{Test sites}

Test sites were selected after reviewing previous biological and water quality assessments [25,26], and sites that exhibited good water quality and a diverse macroinvertebrate assemblage were selected. Honey Creek, Clark County, Ohio (latitude and longitude $\mathrm{N} 39^{\circ} 58^{\prime} 17.8^{\prime \prime} / \mathrm{W} 084^{\circ} 08^{\prime} 07.5^{\prime \prime}$ ) was chosen as a low-order test stream (second order). The sampling sites for the embeddedness chambers were located in a run feature approximately $0.5 \mathrm{~m}$ downstream from a small riffle. The river substrate consisted mainly of cobbles and boulders, with sand and pebbles mixed throughout. Stream depth at the sampling site averaged approximately $0.25 \mathrm{~m}$. The Stillwater River, Miami County, Ohio (latitude and longitude $\left.\mathrm{N} 40^{\circ} 05^{\prime} 54.1^{\prime \prime} / \mathrm{W} 084^{\circ} 21^{\prime} 16.0^{\prime \prime}\right)$ was chosen as a medium-order stream (fourth order). The sampling sites for the embeddedness chambers were located in a run feature approximately 2 to $3 \mathrm{~m}$ downstream from a riffle. The river substrate consisted mainly of cobbles and boulders, with sand and pebbles mixed throughout. Stream depth at the sampling site averaged approximately $0.5 \mathrm{~m}$.

\section{Physicochemical and toxicity characterization}

Stream discharge was monitored to determine whether major fluctuations in discharge occurred. Flow rates were recorded using a Swoffer 3000 flow meter on six occasions over the course of the chamber exposures. All flow rate measurements were conducted immediately downstream from the chambers and at the same location at both sites on each occasion. In addition, a 10-d sediment toxicity test using Hyalella azteca was conducted according to U.S. EPA methods to determine whether any background toxicity was present within the sediments at the sites that might affect macroinvertebrate colonization [27].

Water samples were taken and analyzed for total suspended solids (TSS) on five occasions to determine whether any major fluctuations occurred during the chamber exposures. Water quality parameters (turbidity, dissolved oxygen, specific conductance, temperature, and $\mathrm{pH}$ ) were monitored using a YSI 6920 Sonde.

\section{Chamber design}

Artificial substrate chambers were used to assess aquatic insect colonization and sediment accumulation over periods of 4, 7, and $14 \mathrm{~d}$. The embeddedness chamber was designed to allow organisms and sediment of less than $4 \mathrm{~mm}$ access to the interior of the chamber. The chamber was constructed of cylindrical cellulose acetate butyrate tubing with a $6.7 \mathrm{~cm}$ inner diameter, $7.0 \mathrm{~cm}$ outer diameter, $0.16 \mathrm{~cm}$ wall thickness, and length of $12.7 \mathrm{~cm}$. Two rectangular sections $(8.5 \mathrm{~cm} \times 4.0 \mathrm{~cm})$ were removed from each core tube leaving an $8.5 \mathrm{~cm} \times 1.0 \mathrm{~cm}$ section of the tube remaining intact on the top portion of the chamber for support. Each end of the cylindrical tubing was capped with a polyethylene closure that had approximately onethird of the end portion removed (Fig. 1). Each end cap had nine evenly spaced 4-mm holes drilled into the flat end portion of the cap, which were intended to allow the chamber design to accommodate hyporheic flow. The chamber was then enclosed with the 4.0-mm-diameter opening mesh using silicone sealant. Once complete, the chamber was filled with 110 clear glass spherical marbles (artificial substrate), with a uniform diameter of $14 \mathrm{~mm}$. The nonsecured end cap was placed on the chamber, and the mesh flap was pulled tight over the cap. Chamber covers consisting of a half-cylinder of the cellulose acetate butyrate tubing with a polyethylene closure flap were designed to cover all exposed chamber areas. These coverings minimize any unwanted sediment being deposited into the chambers during deployment and any sediment loss from the chamber on retrieval (covers were removed once chambers had been deployed).

Embeddedness chambers were placed at the head of a run feature. A random sampling scheme was developed to sample the embeddedness chambers for aquatic insects and sediment accumulation at three different time points (Fig. 2). This design accounted for nonuniform stream conditions across the width of the sampling area and for the natural patchy distribution of benthic macroinvertebrates [28].

\section{Chamber deployment}

Three chambers were secured to one metal in situ tray prior to installing the in situ trays (metal grated $13.1 \mathrm{~cm}$ long $\times 15.2 \mathrm{~cm}$ wide $\times 2.1 \mathrm{~cm}$ high trays) in the stream. Once the chamber covers had been installed on each chamber, the in

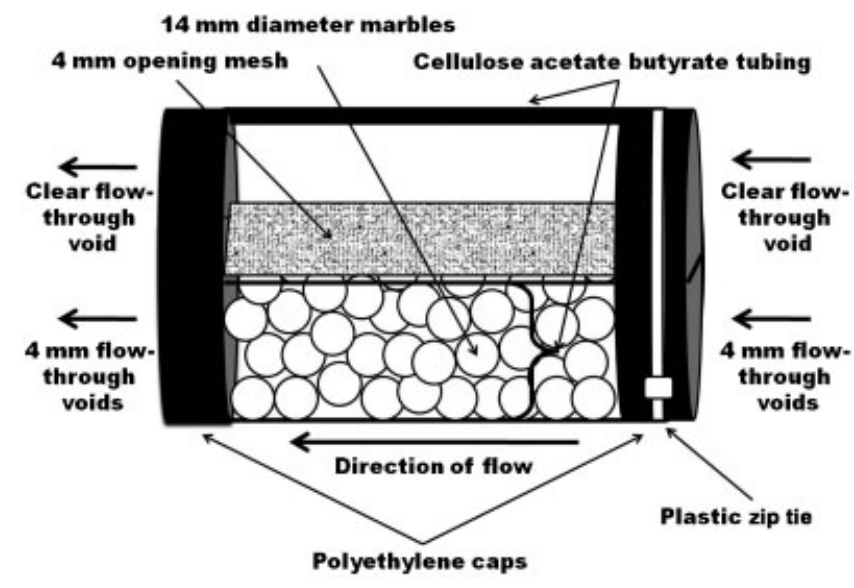

Fig. 1. Embeddedness chamber schematic. 


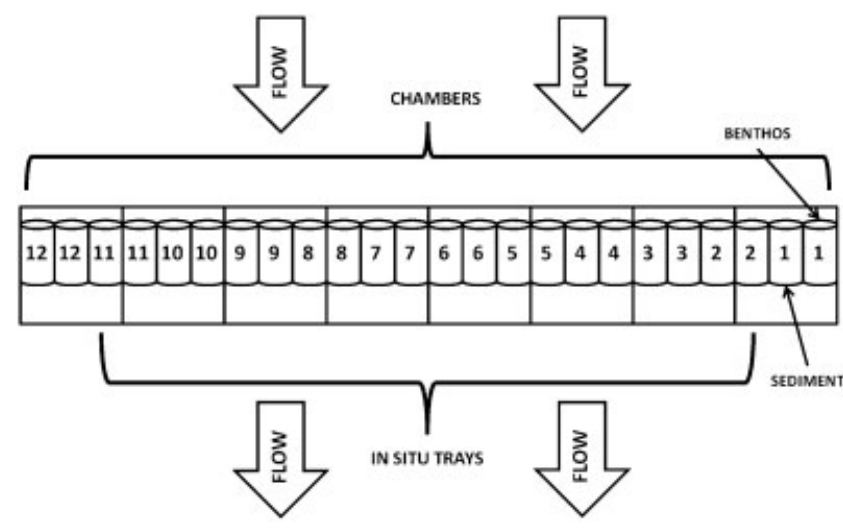

Fig. 2. Diagram of experimental design of the retrieval of chambers. Four embeddedness chamber numbers (both for benthos and sediment) were randomly selected for each of the three sampling events.

situ tray was installed in the stream. The placement area for the in situ tray was prepared by removing enough substrate so that the flat portion of the chamber would be flush with the surrounding undisturbed substrate.

In total, eight in situ trays, totaling 24 chambers, were installed at each site. The substrate was removed to allow tray placement and carefully spread around the chambers. After the site had been allowed to settle for approximately $2 \mathrm{~min}$, the chamber covers were removed. Only the upper halves of the chambers were visible during deployment.

\section{Chamber retrieval}

The chambers were randomly sampled and care was taken not to disturb the substrate upstream or downstream when removing chambers. Chamber covers were installed and the chamber was removed and immediately placed in a watertight plastic bag. Once the chamber had been removed, a small amount of substrate was placed in the space where the chamber previously resided, so that the adjacent chamber's flat mesh portion was flush with the surrounding, undisturbed substrate to reduce turbulence.

\section{Chamber substrate characterization}

Four sediment fractions (gravel $>2 \mathrm{~mm}$, sand $=2 \mathrm{~mm}-$ $250 \mu \mathrm{m}$, silt $=250-63 \mu \mathrm{m}$, and clay $=63-1.2 \mu \mathrm{m}$ ) were analyzed from sediment that had accumulated within the interstitial spaces of the chamber substrate through wet sieving, desiccation, and sequential loss on ignition [29]. The porosity of each chamber was estimated using the bulk density of the chamber sediments (which was determined through the sequential loss on ignition process) and compared with abiotic and biotic endpoints. Organic content was determined after firing the sediment at $550^{\circ} \mathrm{C}$, and carbonate content was determined after firing at $1,000^{\circ} \mathrm{C}$. Determining the organic and carbonate fractions of the embeddedness chamber sediments facilitated the calculation of chamber porosity using the bulk density and the wet sediment volume obtained from this process. Calculation of chamber porosity was estimated using the equation

$$
\begin{aligned}
\rho_{\text {particle }} & =\frac{\left(\mathrm{SW}_{\text {wet sed }}-\mathrm{TW}_{\text {chamber }}\right)-\left(\mathrm{SW}_{\text {wet sed }}-\mathrm{SW}_{\mathrm{DF}}\right)}{\left[\mathrm{Vol}-\left(\frac{\mathrm{SW}_{\text {wet sed }}-\mathrm{SW}_{\mathrm{DF}}}{\rho_{\text {water }}}\right)\right]} \\
& =\mathrm{g} / \mathrm{cm}^{3}
\end{aligned}
$$

where $\mathrm{SW}_{\text {wet sed }}$ is the weight of embeddedness chamber sediment/water (chamber wet wt to clean chamber dry wt; g); $\mathrm{TW}_{\text {chamber }}$ is the tare weight of the embeddedness chamber (test substrate and storage bag included; $\mathrm{g}$ ); $\mathrm{SW}_{\mathrm{DF}}$ is the weight of dried sediment fraction (DF; $2 \mathrm{~mm}, 250 \mu \mathrm{m}, 63 \mu \mathrm{m}$, or $1.2 \mu \mathrm{m} ; \mathrm{g})$; Vol is the volume of wet sediment from chambers $\left(\mathrm{cm}^{3}\right)$; and $\rho_{\text {water }}$ is the density of water $\left(1 \mathrm{~g} / \mathrm{cm}^{3}\right)$.

Each embeddedness chamber that had been designated for sediment analysis was processed to obtain four different grain size fractions (gravel, sand, silt, and clay). Each chamber and the plastic bag in which it was stored (refrigerated at $4^{\circ} \mathrm{C}$ ) were weighed prior to emptying.

In addition to chamber substrate characterization, percentage of embeddedness was estimated with the existing substrate at each site once during the course of the present study using a combination of the Burns method and an additional optional method as described in the Additional Optional Measures section of the U.S. Geological Survey NAWQA optional method [20,21]. Our combined method used the random particle selection aspects of the NAWQA optional method along with the quantitative aspect of the measured embeddedness of the Burns method [20,21]. This combined method consisted of the measured embedded height of the particle (as determined by obvious discoloration) divided by the particle height (as oriented in the stream bed) of the randomly selected particles along the transect. The percentage of embeddedness was determined for each of the 100 samples, and then the site percentage of embeddedness was estimated using the average of the transect particles. Some methods advocate for at least 400 particles to decrease sampling error; however, our selection of the standard 100 particle count has been supported for the adequate characterization of variation of streambed surface sediment within a region [30]. Care was taken to remove substrate particles in the precise orientation at which they occurred in the streambed.

\section{Chamber aquatic insect recruitment}

The embeddedness chambers designated for aquatic insect recruitment were processed in the laboratory and emptied into a sieve stack containing a 5.6-mm sieve for retaining the marbles on top of a $500-\mu \mathrm{m}$ sieve for retaining the invertebrates. The sample retained on the $500-\mu \mathrm{m}$ sieve was rinsed with deionized water to remove any fine particulate matter; the unsorted sample was then preserved in a $70 \%$ ethanol solution. All insects were identified to family level or lowest practical level using the methods of Peckarsky et al. [31] and Merritt et al. [32].

\section{Data analysis}

Several macroinvertebrate metrics (family richness, composition, and tolerance measures) were chosen to assess each sampling site. Significance was determined by running a oneway analysis of variance with Tukey's post hoc test to determine whether there were significant differences between the sampling dates. Numbers data were natural log transformed prior to running statistical analysis to help the data fit the assumption of normal distribution. All proportional data (percentage of abundances) were transformed using an arcsine square root transformation. Regression analyses were run on the wide array of data from the chambers. The biotic metrics were run against abiotic factors such as total dry fraction of sediment, porosity, fractions of the dry sediment weight (>2 mm, $2 \mathrm{~mm}-250 \mu \mathrm{m}, 250-63 \mu \mathrm{m}$, and $63-1.2 \mu \mathrm{m}$ total dry wt), percentage of organic content of chamber sediments, and time. 
Table 1. Measured physicochemical water quality parameters for both study sites

\begin{tabular}{|c|c|c|c|c|c|c|c|}
\hline Date & Site & Cond $(\mu \mathrm{s} / \mathrm{cm})$ & River temperature $\left({ }^{\circ} \mathrm{C}\right)$ & $\mathrm{pH}$ & River DO (mg/L) & Turbidity (NTU) & Flow (cfs) \\
\hline $10 / 1 / 2007$ & $\mathrm{HY} \mathrm{Cr}$ & 772 & 15.6 & - & 7.88 & 0 & 0.314 \\
\hline $10 / 3 / 2007$ & $\mathrm{HY} \mathrm{Cr}$ & 776 & 17.56 & 8.1 & 9.79 & 1.1 & 0.293 \\
\hline $10 / 5 / 2007$ & $\mathrm{HY} \mathrm{Cr}$ & 794 & 18.16 & 7.95 & 7.83 & 0 & 0.312 \\
\hline $10 / 8 / 2007$ & $\mathrm{HY} \mathrm{Cr}$ & 492 & 19.53 & 7.93 & 8.09 & 0.5 & 0.316 \\
\hline $10 / 15 / 2007$ & $\mathrm{HY} \mathrm{Cr}$ & 816 & 13.14 & 7.97 & 8.12 & 1.5 & 0.319 \\
\hline $10 / 1 / 2007$ & SR & 686 & 18.5 & - & 9.49 & - & 0.920 \\
\hline $10 / 3 / 2007$ & SR & 735 & 19.17 & 8.38 & 10.35 & 1.8 & 0.864 \\
\hline $10 / 5 / 2007$ & SR & 772 & 22.01 & 8.37 & 10.08 & 1.8 & 0.916 \\
\hline $10 / 8 / 2007$ & SR & 759 & 23.19 & 8.31 & 9.89 & 2.8 & 0.786 \\
\hline $10 / 12 / 2007$ & SR & 745 & 14.24 & 8.47 & 11.21 & 1 & 0.874 \\
\hline $10 / 15 / 2007$ & $\mathrm{SR}$ & 785 & 15.89 & 8.51 & 13.44 & 0.8 & 0.753 \\
\hline
\end{tabular}

HY $\mathrm{Cr}=$ Honey Creek; SR = Stillwater River; DO = dissolved oxygen; NTU = nephelometric turbidity units; Cfs $=$ cubic feet per second.

\section{RESULTS}

\section{Sediment toxicity}

Results from a two-sample $t$ test show no significant differences in mean survival between Honey Creek sediment $(87.5 \%$ survival, $p=0.138$ ) and the reference (97.5\% survival), or with Stillwater River sediment $(90 \%$ survival, $p=0.391)$ and the reference.

\section{Physicochemical water quality parameters}

Stream discharge was monitored on six occasions over the 4- to 14-d chamber exposure periods to determine whether the chambers would be effective in capturing sediment accumulation occurring during steady stream flow conditions. No major fluctuations in discharge or rainfall $(0.10 \mathrm{~cm}$ during the study) at the two sites were recorded, and discharge remained relatively stable over the 14-d exposure period. The Honey Creek site maintained a mean flow of $0.311 \mathrm{~m}^{3} / \mathrm{s}$ with flow increasing slowly from $0.293 \mathrm{~m}^{3} / \mathrm{s}$ on October 3,2007 to $0.319 \mathrm{~m}^{3} / \mathrm{s}$ on October 15, 2007. The Stillwater River site experienced small fluctuations in flow and had a mean flow of $0.852 \mathrm{~m}^{3} / \mathrm{s}$ (Table 1) over the exposure period. The lowest and highest flows were $0.753 \mathrm{~m}^{3} / \mathrm{s}$ and $0.920 \mathrm{~m}^{3} / \mathrm{s}$, respectively.
Water samples were taken at both study sites on three occasions over the chamber exposure periods and analyzed for TSS. Concentrations obtained from the Honey Creek water samples were recorded with the lowest TSS concentration being $3.8 \mathrm{mg} / \mathrm{L}$ and the highest concentration of $9.0 \mathrm{mg} / \mathrm{L}$. Stillwater River TSS concentrations exhibited a low of $1.3 \mathrm{mg} / \mathrm{L}$ and a high of $6.0 \mathrm{mg} / \mathrm{L}$.

Turbidity measurements taken during the chamber exposure periods indicate that there was very little fluctuation at both Honey Creek and the Stillwater River. Turbidity at Honey Creek varied from near zero to only 1.5 nephelometric turbidity units. Turbidity readings from the Stillwater River varied from 0.8 nephelometric turbidity units to a maximum of 2.8 nephelometric turbidity units.

\section{Embeddedness}

The results for percentage of embeddedness using a combination of the Burns Method and the NAWQA optional method indicate that both sites were experiencing relatively low embeddedness $(31.5 \%$ at Honey Creek, $27.2 \%$ at Stillwater River). Percentage of embeddedness values for both sites fall into the range of what has been found not to affect macroinvertebrates detrimentally $[4,33,34]$.

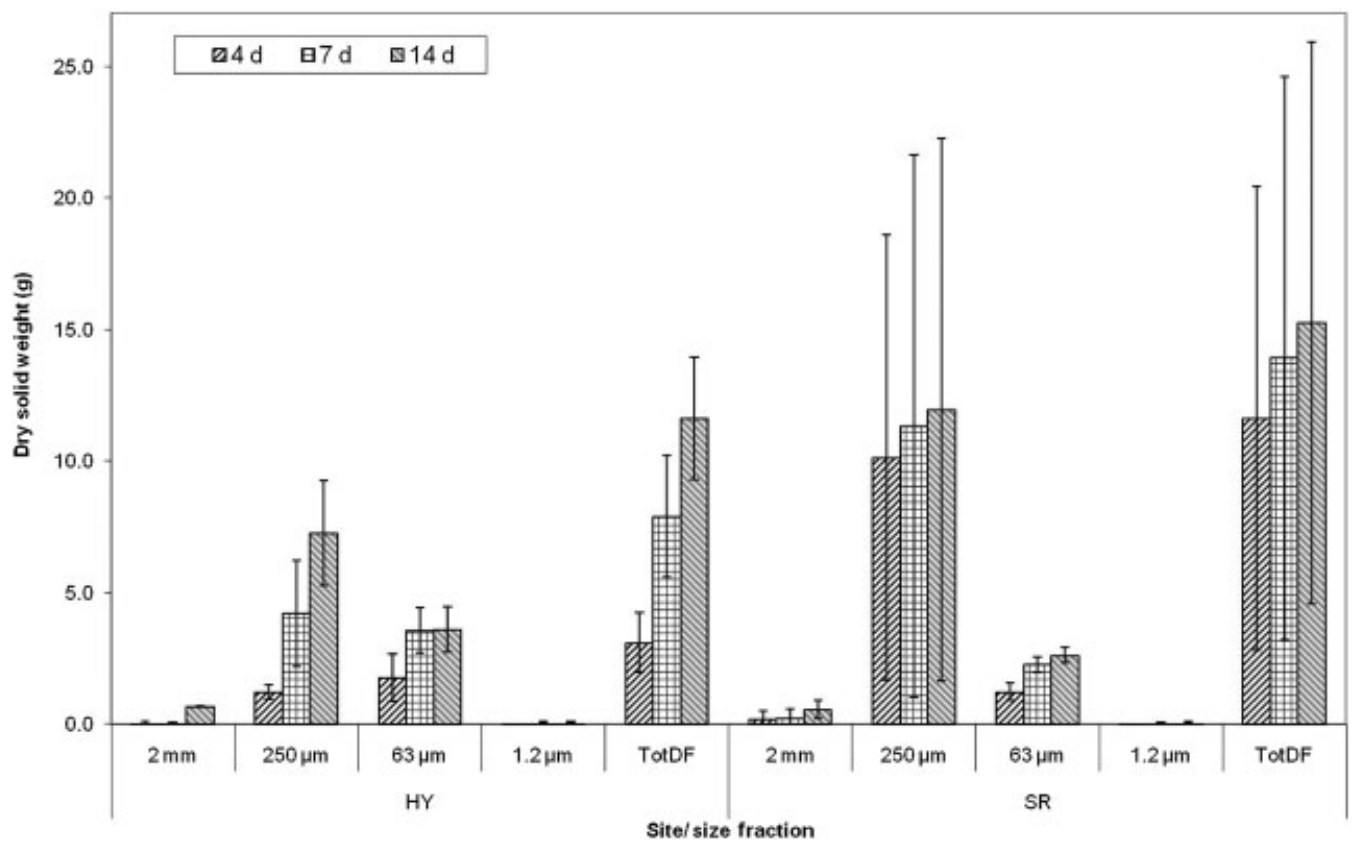

Fig. 3. Temporal representation of dry fraction weights of chamber sediment accumulated for both Honey Creek (HY) and Stillwater River (SR). 
Table 2. Significant observations from regression analysis between embeddedness chamber biotic and abiotic parameters (Honey Creek, New Carlisle, Ohio, USA)

\begin{tabular}{|c|c|c|c|c|c|c|c|c|c|c|c|c|}
\hline & \multicolumn{3}{|c|}{ Porosity } & \multicolumn{3}{|c|}{ Time } & \multicolumn{3}{|c|}{ DF $63 \mu \mathrm{m}-1.2 \mu \mathrm{m}$} & \multicolumn{3}{|c|}{$\%$ Organic } \\
\hline & $p$ & $r^{2}$ & $s$ & $p$ & $r^{2}$ & $s$ & $p$ & $r^{2}$ & $s$ & $p$ & $r^{2}$ & $s$ \\
\hline Percentage of Ephemeroptera & & & & & & & & & & 0.009 & $28.5 \%$ & $(-)$ \\
\hline No. of Plecoptera taxa & & & & & & & & & & 0.006 & $30.5 \%$ & $(-)$ \\
\hline Total insects & & & & 0.000 & $54.1 \%$ & $(+)$ & & & & & & \\
\hline No. of EPT taxa & & & & 0.005 & $31.4 \%$ & $(+)$ & & & & & & \\
\hline No. of Chironomidae & & & & 0.002 & $36.0 \%$ & $(+)$ & 0.005 & $32.0 \%$ & $(+)$ & & & \\
\hline No. of Hydropsychidae & & & & 0.001 & $41.3 \%$ & $(+)$ & 0.003 & $34.7 \%$ & $(+)$ & & & \\
\hline DF $2 \mathrm{~mm}$ to $250 \mu \mathrm{m}$ & 0.037 & $43.7 \%$ & $(-)$ & & & & & & & & & \\
\hline DF $63 \mu \mathrm{m}$ to $1.2 \mu \mathrm{m}$ & 0.006 & $30.5 \%$ & $(-)$ & & & & & & & & & \\
\hline
\end{tabular}

$\mathrm{DF}=$ dry fraction of sediment; $s=$ slope; EPT $=$ Ephemeroptera, Trichoptera, and Plecoptera.

\section{Grain size fractional analysis of chamber sediment}

Results from the chamber processing indicate that the majority of the sediment that accumulated was in the size range of $<2 \mathrm{~mm}$ to $>63 \mu \mathrm{m}$ (Fig. 3). At day 4 , the 63- to $250-\mu \mathrm{m}$ fraction accounted for the majority $(57 \%)$ of the sediment accumulating in the embeddedness chambers deployed at Honey Creek. However, after $4 \mathrm{~d}$, there was a clear increasing trend over time in the $250-\mu \mathrm{m}$ to $2-\mathrm{mm}$ size fraction $(53 \%$ and $62 \%$, respectively). The Stillwater River results showed the $250-\mu \mathrm{m}$ to $2-\mathrm{mm}$ size fraction clearly to be the majority of the sediment accumulating over the 4-, 7-, and 14-d sampling points $(87,82$, and $78 \%$, respectively). Results indicated a decrease in dominance of the $250-\mu \mathrm{m}$ to $2-\mathrm{mm}$ size fraction over time, along with an increase in the 63- to $250-\mu \mathrm{m}$ size fraction (Fig. 3). The $>2-\mathrm{mm}$ size fraction was a relatively small percentage of the overall sediment accumulating at both sites and at all time points (Fig. 3). The 1.2- to 63- $\mu \mathrm{m}$ size fraction remained relatively stable throughout the entire chamber exposure period (Fig. 3). Regression analysis revealed negative correlations between porosity and the total dry fraction and also between the $1.2-$ to $63-\mu \mathrm{m}$ and the $250-\mu \mathrm{m}$ to $2-\mathrm{mm}$ dry

Table 3. Significant observations from regression analysis between chamber biotic and abiotic parameters (Stillwater River, Covington, Ohio, USA)

\begin{tabular}{|c|c|c|c|c|c|c|}
\hline & \multicolumn{3}{|c|}{ Porosity } & \multicolumn{3}{|c|}{ DF $250-63 \mu \mathrm{m}$} \\
\hline & $p$ & $r^{2}$ & $s$ & $p$ & $r^{2}$ & $s$ \\
\hline Total insects & & & & 0.016 & $45.6 \%$ & $(+)$ \\
\hline No. of taxa & & & & 0.001 & $65.6 \%$ & $(+)$ \\
\hline No. of Ephemeroptera taxa & & & & 0.010 & $50.4 \%$ & $(+)$ \\
\hline Percentage of Ephemeroptera & & & & 0.017 & $45.2 \%$ & $(+)$ \\
\hline No. of Trichoptera taxa & & & & 0.023 & $41.8 \%$ & $(+)$ \\
\hline Percentage of Trichoptera & & & & 0.004 & $57.5 \%$ & $(+)$ \\
\hline No. of EPT taxa & & & & 0.001 & $68.2 \%$ & $(+)$ \\
\hline Percentage of EPT & & & & 0.001 & $69.9 \%$ & $(+)$ \\
\hline Percentage of Chironomidae & & & & 0.001 & $65.6 \%$ & $(-)$ \\
\hline $\begin{array}{l}\text { Percentage of grazers } \\
\text { and scrapers }\end{array}$ & & & & 0.031 & $38.6 \%$ & $(+)$ \\
\hline Percentage of shredders & & & & 0.011 & $49.0 \%$ & $(+)$ \\
\hline Percentage of dominant taxon & & & & 0.002 & $63.8 \%$ & $(-)$ \\
\hline Family biotic index & & & & 0.002 & $37.4 \%$ & $(-)$ \\
\hline No. of Hydropsychidae & & & & 0.020 & $43.3 \%$ & $(+)$ \\
\hline Total DF & 0.008 & $51.7 \%$ & $(-)$ & & & \\
\hline DF $2 \mathrm{~mm}$ to $250 \mu \mathrm{m}$ & 0.014 & $46.9 \%$ & $(-)$ & & & \\
\hline DF $250 \mu \mathrm{m}$ to $63 \mu \mathrm{m}$ & 0.008 & $52.1 \%$ & $(-)$ & & & \\
\hline Percentage of organic & 0.042 & $35.1 \%$ & $(+)$ & & & \\
\hline
\end{tabular}

$\mathrm{DF}=$ dry fraction of sediment $s=$ slope $; \mathrm{EPT}=$ Ephemeroptera, Trichoptera, and Plecoptera. fractions of chamber sediments at the Honey Creek site (Table 2). Regression analysis revealed negative correlations between porosity and the total dry fraction (63- to $250-\mu \mathrm{m}$ dry fraction and the $250-\mu \mathrm{m}$ to $2-\mathrm{mm}$ dry fraction) and percentage of organic content of chamber sediments at the Stillwater River site (Table 3 ). The steady increase in sediment (total dry fraction) at both sites indicates that the chambers had yet to reach a dynamic equilibrium with the surrounding substrate (Fig. 3). However, mean bulk porosity within the embeddedness chambers showed an overall decreasing trend from day 4 to day 14 at both sites (Table 4), which reflects the corresponding steady increase in sediment within the chambers (Fig. 3).

\section{Aquatic insect characterization}

The aquatic insect results from adjacent undisturbed grab samples show both sites exhibiting high values of the following metrics: percentages of Trichoptera; percentages of Ephemeroptera, Plecotera, Trichoptera (EPT) taxa; percentages of filterers; and percentages of dominant taxa (Fig. 4). These results indicate that the bulk of the aquatic insect assemblage comprises mainly taxa that have a moderate pollution tolerance. The U.S. EPA rapid bioassessment protocol results from Honey Creek indicate that Trichoptera taxa are the primary contributors to the percentage of EPT taxa metric (the majority being Hydropsychidae; Fig. 4). Contrary to the results for Honey Creek, the Stillwater River metric results indicate that Ephemeroptera taxa were the primary contributors to the percentage of EPT taxa (the majority being Heptageniidae and Tricorythidae). Both dominant families of Ephemeroptera taxa (Heptageniidae and Tricorythidae) have moderate pollution tolerance values (4), and both of these taxa colonized the chambers at the Stillwater River site.

\section{Chamber metrics}

Both sites exhibited a steady increase over time in the total number of insects colonizing the chambers (Figs. 5 and 6). There was a significant difference in number of taxa $(p=0.012)$ increasing between the 4-d and 14-d sampling events at Honey Creek. There was also a significant difference between the 4-d

Table 4. Calculated mean porosity of chamber sediments for both sites

\begin{tabular}{lrr}
\hline Sampling period (d) & HY Cr & SR \\
\hline 4 & 72.01 & 16.13 \\
7 & 8.79 & 4.52 \\
14 & 20.08 & 4.49 \\
\hline
\end{tabular}

$\mathrm{HY} \mathrm{Cr}=$ Honey Creek; SR $=$ Stillwater River. 


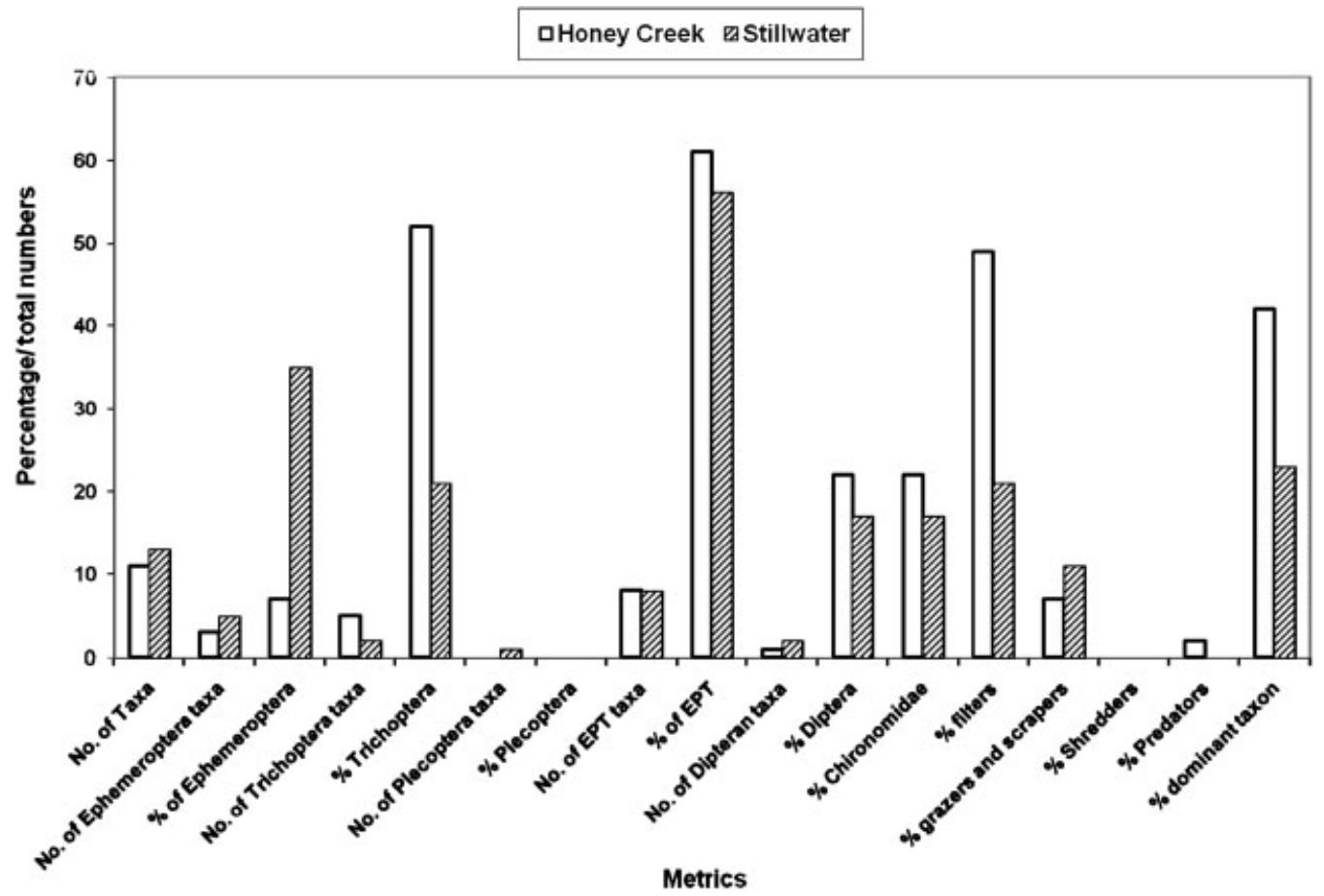

Fig. 4. Honey Creek and Stillwater River macroinvertebrate rapid bioassessment protocol results sampled on September 28, 2007. EPT =Ephemeroptera, Plecotera, Trichoptera.

and 7-d samples in the number of Trichoptera taxa $(p=0.048)$ increasing at Honey Creek (Fig. 5 and 6). Significant differences between 4-d and 14-d sampling events were found in the following metrics at Stillwater River: percentages of Trichoptera $(p=0.046)$ and percentages of taxa $(p=0.027)$ increased over time, and percentages of Diptera $(p=0.024)$ decreased over time (Figs. 5 and 6).

Regression analyses run on the benthic macroinvertebrate metric data from both Honey Creek and the Stillwater River resulted in numerous significant $r^{2}$ values and $p$ values showing moderate correlations for most significant tests (Table 2 and 3 ). The correlation between porosity and total dry fraction of chamber sediments (Stillwater River, $r^{2}=51.7 \%, p=0.008$ ) showed a relatively strong negative correlation (Table 3 ). Correlations between sediment and porosity observed at the Stillwater River suggest that the smaller fractions might have the most influence on porosity $\left(\mathrm{DF}_{250}, r^{2}=46.9 \%, p=0.014 ; \mathrm{DF}_{63}\right.$, $r^{2}=52.1 \%, p=0.008$; Table 3). Similar correlations between porosity and sediment with the Honey Creek chamber data also suggested the smaller fractions were more related to changes in porosity (total $\mathrm{DF}_{250}, r^{2}=43.7 \%, p=0.037 ; \mathrm{DF}_{1.2}, r^{2}=30.5 \%$, $p=0.006$, negative correlation; Table 2).

The benthic macroinvertebrate metric data for Honey Creek showed a variety of significant $p$ values when run against the

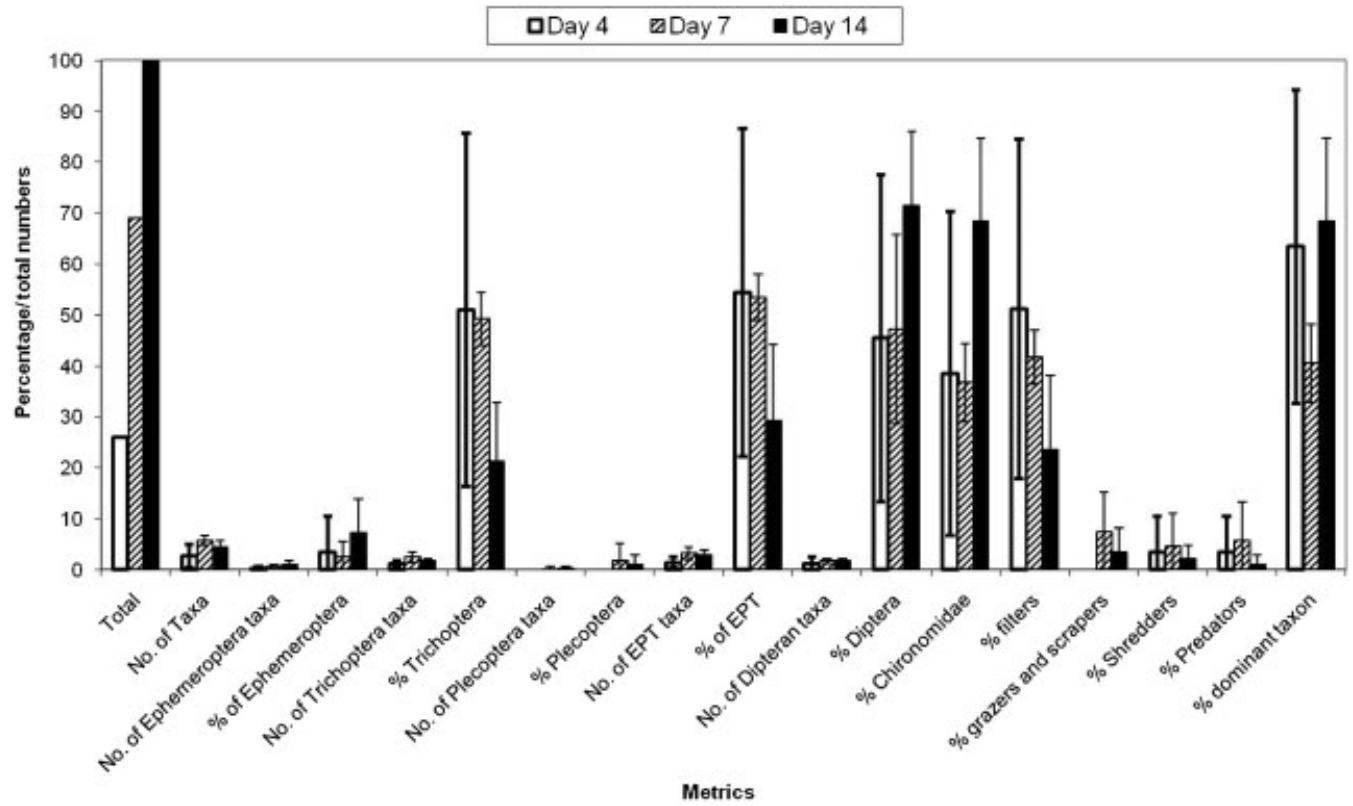

Fig. 5. Chamber macroinvertebrate metrics for the Honey Creek site. EPT = Ephemeroptera, Plecotera, Trichoptera. 


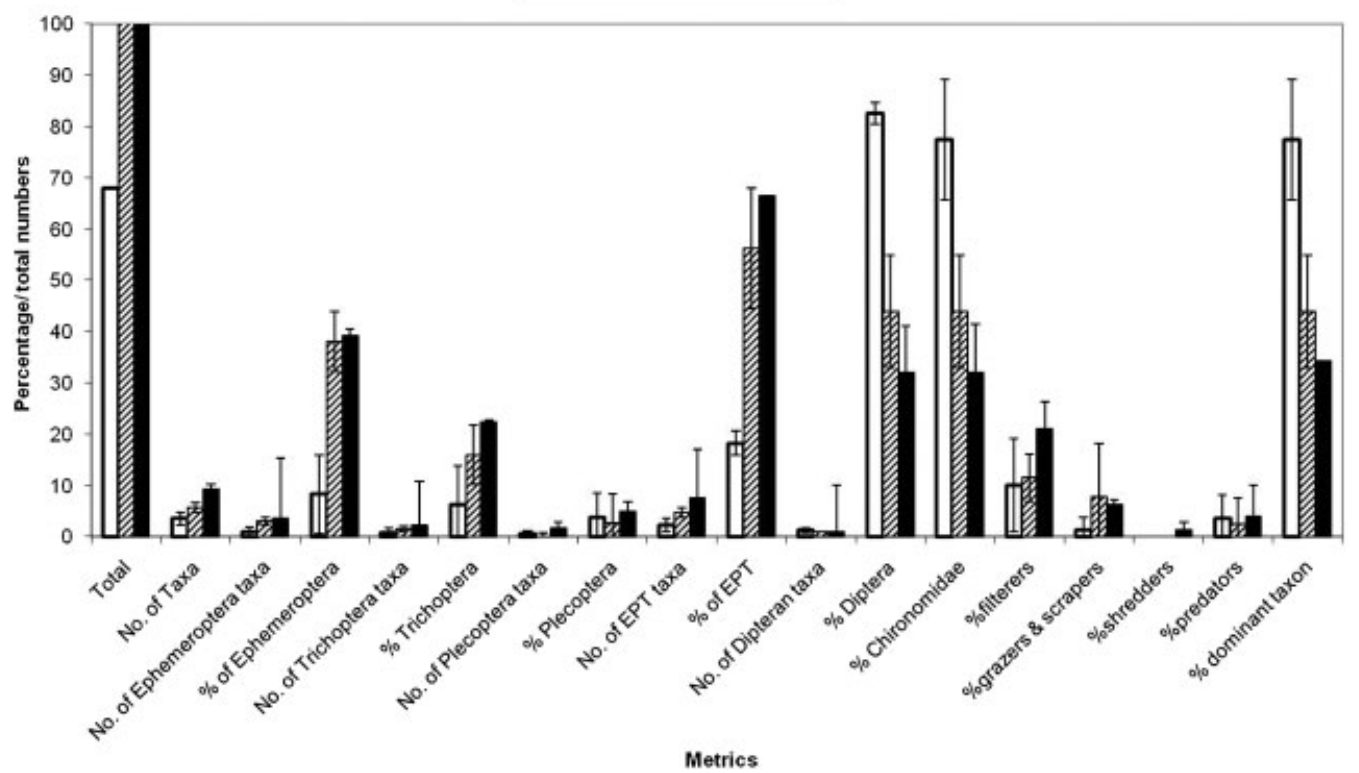

Fig. 6. Chamber macroinvertebrate metrics for the Stillwater River site. EPT =Ephemeroptera, Plecotera, Trichoptera.

chamber sediment data (Table 2), yet most of the correlation values were relatively weak. Significant correlations were between the $63-\mu \mathrm{m}$ to $1.2-\mu \mathrm{m}$ dry fraction and the number of Chironomidae $\left(r^{2}=32.0 \%, p=0.005\right)$ and the number of Hydropsychidae $\left(r^{2}=34.7 \%, p=0.003\right.$; Table 2$)$. The Stillwater River data showed significant correlations between benthic macroinvertebrate metrics and the 250- to 63- $\mu \mathrm{m}$ dry sediment fraction, with 14 of the 20 metrics exhibiting a significant correlation (primarily positive; Table 3 ).

\section{DISCUSSION}

The bulk of embeddedness techniques estimate (or measure in some cases) substrate particle height and the corresponding sediment height on the particle to determine the degree of substrate embeddedness. These methods, although considered more visually subjective, tend to require a relatively low level of effort and can provide insight into potential substrate and habitat conditions. What is unique about the method described in the present study is that it yields replicated data on sediment size fractions and porosity as well as aquatic insect recruitment and allows these variables to be compared directly. It should be noted, however, that this novel method is more labor intensive than other conventional techniques that yield only substrate data or macroinvertebrate data individually. Direct comparisons between current embeddedness methodologies and our method are not practical because of procedural and quantification differences; however, the method does allow for a characterization of the relationships between sediment siltation and embeddedness and its associated effects on indigenous benthic macroinvertebrates colonizing those sediments.

In relatively brief periods ( $<14 \mathrm{~d})$, aquatic insect recruitment showed expected responses in the presence of increasing sedimentation rates. More extended exposure times for benthic macroinvertebrate colonization often span 5 weeks [35-37], but shorter periods of 9 to $14 \mathrm{~d}$ have been reported [38]. The short exposure periods used for validating this chamber occurred during low-flow conditions, minimizing any confounding effects from other stressors such as elevated contaminants or TSS during high-flow events.
Percentage of embeddedness measurements from each site indicate that these stretches of streams were not experiencing excessive stress resulting form substrate embeddedness. Percentage of embeddedness results for both sites are below what has been considered to be the normal range before detrimental effects are seen in the macroinvertebrate community and may be considered close to an embeddedness standard/target in North America (approximately 25-35\%) [4,33,34,39].

We have demonstrated that this chamber design is capable of capturing both accumulating sediment within the substrate and colonizing aquatic insects; however, the mesh size selected may determine whether access is restricted to larger invertebrates. Observations of several net spinning caddisfly larvae cases inside the chambers and adjacent to the end cap holes during processing indicate that the chamber design seemed to facilitate adequate subsurface water flow. The glass marbles serving as artificial substrate were cleaned easily of any visible organic and inorganic matter during chamber processing; however, a biofilm developed on the surface of the artificial substrate, which we believe would not have had a significant contribution to the substrate organic content that was determined through the loss on ignition process.

Sand and silt fractions were the dominant particles depositing within the chambers and increased with time. The term "embedding" is used loosely here because the sediment within the chambers continued to increase steadily over $14 \mathrm{~d}$ of exposure, as would be expected when introducing clean substrate into systems experiencing low embeddedness (27-32\%). Colonization of aquatic insects increased steadily over time as well at both sites. Longer chamber exposure times would, more than likely, result in sediment embeddedness that more reflects those conditions of neighboring sediments. The aquatic insects colonizing the chambers have a moderate pollution tolerance. The initial colonization was made by organisms known as early colonizers and opportunists and suggests that the chambers mimic phenomena observed in many systems. The significant correlations between the majority of benthic macroinvertebrate metrics and the silt fraction is of interest in that the sand size fraction is the dominant proportion of the total sediment at the 
sites. Had the dominant fraction been silt, this would suggest that the correlations between the metrics and the particular sediment size were occurring mainly because of proportionality [32].

\section{CONCLUSIONS}

The in situ embeddedness chamber holds promise in experimental benthic macroinvertebrate colonization studies, particularly when assessing the role of siltation and embeddedness as potential stressors. Further research is needed to determine how well the chambers reflect the embeddedness of site sediments. Evaluating responses during different flow regimes and time periods may also provide information useful in discerning the effect of disturbance events on benthic communities and embeddedness. Disturbances have been accepted as critical to the community structure and dynamics of lotic communities [40]. The chamber designed exhibits potential as a tool for assessing macroinvertebrate resilience after disturbances such as scour/flood events and rewetting events after periods of no flow. Inclusion of noninsect taxa into the analysis may provide the additional significance needed to validate assumptions. The uniform size of the artificial substrate (i.e., marbles) does not mimic a more diverse size stream substrate, and future modifications of this design should include a range of substrate sizes and the use of site substrates that have had embedded sediments removed. This approach provides additional means of relating exposure to effects in situ and potentially improving determinations of stressor causality. This approach has also proved that the chambers and methods can be used to capture both sediment and aquatic macroinvertebrate recruitment. This may provide a unique opportunity to investigate the relationships between sediment composition and community structure, in particular, to investigate the rate of recovery of particular taxa over a range of particles on the smaller end of the sediment distribution scale. This relationship, coupled with the possibility of assessing the deposited sediment for nutrient or chemical presence, would provide a range of opportunities for discovery.

Acknowledgement-We thank P. Anderson, K. Taulbee, K. Simpson, and C. Cloran for help with this research both in the field and in the laboratory. We also thank the two anonymous reviewers for their constructive comments.

\section{REFERENCES}

1. Burton GA Jr. 1991. Assessing the toxicity of freshwater sediments. Environ Toxicol Chem 10:1585-1627.

2. Lemly AD. 1982. Modifications of benthic insect communities in polluted streams: Combined effects of sedimentation and nutrient enrichment. Hydrobiologica 87:229-245.

3. Newcombe CP, MacDonald DD. 1991. Effects of suspended sediments on aquatic ecosystems. North Am J Fisheries Manag 11:72-82.

4. Waters TF. 1995. Sediment in Streams: Sources, Biological Effects and Control. American Fisheries Society, Monograph 7, Bethesda, MD, USA.

5. Wood PJ, Armitage PD. 1997. Biological effects of fine sediment in the lotic environment. J Environ Manag 21:203-217.

6. U.S. Environmental Protection Agency. 2006. Wadeable streams assessment: A collaborative survey of the nation's streams. EPA 841B-06-002. Washington, DC.

7. Hynes HB. 1970. The Ecology of Running Waters. Liverpool University Press, Liverpool, United Kingdom.

8. Oschwald WR. 1972. Sediment-water interactions. J Environ Qual $1: 360-366$

9. Sutherland AB, Culp JM, Benoy GA. 2010. Characterizing deposited sediment for stream habitat assessment. Limnol Oceanogr Methods 8:30-44.

10. Brunke M, Gonser T. 1997. The ecological significance of exchange processes between rivers and groundwater. Freshwater Biol 37:1-33.
11. Rehg KJ, Packman AI, Ren J. 2005. Effects of suspended sediment characteristics and bed sediment transport on streambed clogging. Hydrol Process 19:413-427.

12. Herbst DB, Cooper SD. 2010. Before and after the deluge: Rain-on-snow flooding effects on aquatic invertebrate communities of small streams in the Sierra Nevada, California. J North Am Benthol Soc 29:1354-1366

13. Collier KJ, Quinn JM. 2003. Land-use influences macroinvertebrate community response following a pulse disturbance. Freshwater Biol 48:1462-1481.

14. Fuller RL, Griego C, Muehlbauer JD, Dennison J, Doyle MW. 2010. Response of stream macroinvertebrates in flow refugia and high-scour areas to a series of floods: A reciprocal replacement study. J North Am Benthol Soc 29:750-760.

15. Larsen S, Pace G, Ormerod SJ. 2011. Experimental effects of sediment deposition on the structure and function of macroinvertebrate assemblages in temperate streams. River Res Applic 27:257-267.

16. Runde JM, Hellenthal RA. 2000. Behavioral responses of Hydropsyche sparna (Trichoptera: Hydropsychidae) and related species to deposited bedload sediment. Environ Entomol 29:704-709.

17. Reice SR, Wissmar RC, Naiman RJ. 1990. Disturbance regimes, resilience, and recovery of animal communities and habitats in lotic ecosystems. J Environ Manag 14:647-659.

18. Sylte TL, Fischenich JC. 2002. An evaluation of embeddedness measurement techniques. Technical Report ERDC TN-EMRRP-SR36. U.S. Army Corps of Engineers Research and Development Center, Vicksburg, MS.

19. Sennatt KM, Salant NL, Renshaw CE, Magilligan FJ. 2006. Assessment of methods for measuring embeddedness: Application to sedimentation in flow regulated streams. J Am Water Resour Assoc 42:1671-1682.

20. Burns DC, Edwards RE. 1985. Embeddedness of salmonid habitat of selected streams on the Payette National Forest. U.S.D.A. Forest Service, Payette National Forest, McCall, ID.

21. Fitzpatrick FA, Waite IR, D'Arconte PJ, Maupin MA, Gurtz ME. 1998. Revised methods for characterizing stream habitat in the National Water Quality Assessment Program. Water Resources Investigations Report 98-4052, U.S. Geological Survey, Raleigh, NC.

22. Osmundson DB, Scheer BK. 1998. Monitoring cobble-gravel embeddedness in the streambed of the upper Colorado River, 1996-1997. Final Report, U.S. Fish and Wildlife Service, Grand Junction, CO.

23. Lazorchak JM, Klemm DJ, Peck DV. 1998. Environmental monitoring and assessment program-surface waters: Field operations and methods for measuring the ecological condition of wadeable streams. EPA/620/ R-94/004F, U.S. Environmental Protection Agency, Washington, DC.

24. Barbour MT, Gerritsen J, Snyder BD, Stribling JB. 1999. Rapid bioassessment protocols for use in wadeable streams and rivers: Periphyton, benthic macroinvertebrates and fish. EPA841-B-99002. U.S. Environmental Protection Agency, Office of Water, Washington, DC.

25. Ohio Environmental Protection Agency. 1996. Biological and water quality study of the Upper Great Miami River and selected tributaries. Report MAS/1995-12-13. Columbus, OH, USA.

26. Ohio Environmental Protection Agency. 2001. Biological and water quality study of the Stillwater River watershed. Report MAS/2000-12-8. Columbus, $\mathrm{OH}$, USA.

27. U.S. Environmental Protection Agency. 2000. Methods for measuring the toxicity and bioaccumulation of sediment-associated contaminants with freshwater invertebrates. EPA/600/R-99/064. Washington, DC

28. Pringle CM, Naiman RJ, Bretschko G, Karr JR, Oswood MW, Webster JR, Welcomme RL, Winterbourn MJ. 1988. Patch dynamics in lotic systems: The stream as a mosaic. J North Am Benthol Soc 7:503-524.

29. Dean WE. 1974. Determination of carbonate and organic matter in calcareous sediments and sedimentary rocks by loss on ignition: Comparison with other methods. J Sediment Petrol 44:242-248.

30. Faustini JM, Kaufmann PR. 2007. Adequacy of visually classified particle count statistics from regional stream habitat surveys. J Am Water Resour Assoc 43:1293-1315.

31. Peckarsky BL, Fraissinet MA, Penton MA, Conklin DJ Jr. 1990. Freshwater Macroinvertebrates of Northeastern North America. Cornell University Press, Ithaca, NY, USA.

32. Merritt RW, Cummins KW, Berg MB. 2008. An Introduction to the Aquatic Insects of North America. Kendall/Hunt, Dubuque, IA, USA.

33. Bjornn TC, Brusven MA, Molnau MM, Watts FJ, Wallace RL, Neilson DR, Sandine MF, Stuehrenberg LC. 1974. Sediment in streams and its effect on aquatic life. OWRT Project No. B-025-IDA. Research Technical Report. Water Resources Research Institute, University of Idaho, Moscow, ID, USA 
34. Bjornn TC, Brusven MA, Molnau MP, Milligan JH. 1977. Transport of granitic sediment in streams and its effects on insects and fish. Bulletin 17. University of Idaho, Moscow, ID, USA.

35. Roby KB, Newbold JD, Erman DC. 1978. Effectiveness of an artificial substrate for sampling macroinvertebrates in small streams. Freshwater Biol 8:1-8.

36. Shaw DW, Minshall GW. 1980. Colonization of an introduced substrate by stream macroinvertebrates. Oikos 34:259-271.

37. Lamberti GA, Resh VH. 1985. Comparability of introduced tiles and natural substrates for sampling lotic bacteria, algae and macroinvertebrates. Freshwater Biol 15:21-30.
38. Wise DH, Molles MC. 1979. Colonization of artificial substrates by stream insects: Influence of substrate size and diversity. Hydrobiologica 65:69-74.

39. Caux PY, Moore DRJ, MacDonald D. 1997. Ambient water quality guidelines (criteria) for turbidity, suspended and benthic sediments. British Columbia Ministry of Environment, Victoria, British Columbia, Canada.

40. Resh VH, Brown AV, Covich AP, Gurtz ME, Li HW, Minshall GW, Reice SR, Sheldon AL, Wallace JB, Wissmar RC. 1988. The role of disturbance in stream ecology. J North Am Benthol Soc 7:433455 . 